\title{
Aspects of Human-Centred Design in HCI with Older Adults: Experiences from the Field
}

\author{
Ana Correia de Barros, Sílvia Rêgo, and João Antunes \\ Fraunhofer Portugal AICOS, Porto, Portugal \\ \{ana.barros, silvia.rego, joao.antunes\} @fraunhofer.pt
}

\begin{abstract}
Common characteristics of older adults have led to the rise of recommendations to conduct user research and testing with this particular age group. Even though guidelines exist regarding human-centred design with older adults, there are not many reports on experiences with creating and maintaining elderly user groups for design and research purposes. This paper reviews previous reports in the literature about user groups and adds i) results of qualitative research about the experience of researchers who built their entire professional experience with user groups of older adults, along with ii) the authors' own account of building and maintaining an elderly user group for years. The paper provides recommendations for recruiting, maintaining and motivating elderly user groups towards participation in HCI design and research activities, along with suggestions of strategies to use during field work.
\end{abstract}

Keywords: Human-centred design, older adults, interviews, recommendations, qualitative methods, user recruitment, user group.

\section{Introduction}

The World population is getting older. The Eurostat reports an inversion of the demographic pyramid and sharp ageing of the population in Europe until 2060 [1]. With ageing, several impairments (e.g. sensorial, motor, and psychological) are likely to come about which, in turn, may have effects on people's activities of daily living, independence, or quality of life. Also rising is the array of Information and Communication Technologies (ICT), which are becoming increasingly sophisticated and hold the promise of bringing health care into older adults' homes [2].

However, solutions designed to be used by this age group must take into account natural ageing decline and the implications it may have on the interaction with ICT. On the other hand, a thorough knowledge of people's needs, expectations and attitudes towards ICT is needed so that solutions being designed indeed meet end-users' needs and are regarded by the latter as appealing.

In order to achieve this purpose, many authors agree, users must be invited to be active participants in the design of these technologies [3]. Designers can only go so far in trying to put themselves into users' shoes and the more distant the experiences of end-users and those of designers, the more difficult the challenges become [4]. 
In the European Ambient Assisted Living Joint Programme, for instance, the involvement of end-users through end-user organisations is indeed mandatory ${ }^{1}$.

While there are reports on how to conduct research activities or on how to set up test sessions with older adults, literature is scarce on the latter and scarcer on what is needed to create and maintain a user group for the purpose of human-centred design (HCD) activities that need to involve older adults, caregivers and other stakeholders. Nevertheless, there are research groups who have engaged in these activities and could share their experience with the community towards promoting the practice of HCD.

This paper i) gathers information from different sources regarding this matter, ii) reports experience from the field in building a user network of older adults, and iii) illustrates some points through statements provided by our centre's researchers about their experience and challenges in conducting HCD with older adults. The experiences from the field come from a user network of older adults and caregivers that we have created and maintained at our research centre since 2011-network Colaborar ${ }^{2}$. The network has been growing over time, having at one point reached 400 users, and has supported over $1000 \mathrm{HCD}$ activities required by the manifold research projects at the centre, which is related to ICT solutions towards independent living in old age. Researchers' statements used along the paper were gathered during semi-structured interviews, the major outcomes of which are reported elsewhere [5].

\section{Previous Work}

Conducting research with and about older adults is challenging in different fields, namely in clinical research. Mody and co-workers [6] share methods for the effective recruitment and retention of older adults for research purposes. The methods target four main goals: attaining a representative sample, promoting participation of older adults and other stakeholders in the research, assess feasibility in advance, and retain the participants in the particular study.

Working with older adults in Human-Computer Interaction (HCI) requires specific care not only regarding design, but also regarding the process itself, and how one must prepare sessions, treat participants or deal with idiosyncrasies of the age group [7]. Rubin and Chisnell [7] have laid out recommendations to address these issues.

Lindsay and co-workers [8] have documented their experience, findings and methods extensively after using participatory design with older adults and people with specific impairments (e.g. dementia). They have developed their own method on top of 4 main challenges they identified from previous work, that were related to focus and meeting structure, representation and taking action, ability to envision future concepts, and design beyond tasks (p. 1201).

Gregor and Newell [9] have made the case for 'User sensitive inclusive design', an approach to allow and encourage designers to accommodate diversity within the group of 'older adults', which, the authors argue, is far from homogeneous. The authors

\footnotetext{
${ }^{1}$ http: / / www . aal-europe.eu/get-involved/who-can-apply/

${ }^{2}$ www. colaborar. fraunhofer.pt
} 
claim that the approach allows overcoming the drawbacks found in traditional usercentred design (UCD) techniques, which are meant for more homogeneous groups.

Researchers from the Universities of Dundee, Abertay Dundee and Glasgow, amongst whom were A. F. Newell and Peter Gregor cited above, have concluded that traditional UCD methods used in HCI require some adaptations in order to be effectively used when working with and for older adults [10]. Through the UTOPIA project, the researchers have created a database of 160 individuals for research purposes and have outlined the methods used to efficiently elicit requirements about new technologies from older adults. The methods begin with the work towards the creation of a partnership with end-users and the maintenance of it throughout the research and design process.

Bringing end-users into the design team, a principle of participatory design, has long been praised within the Inclusive Design community. Julia Cassim, through her 'Design Challenges' [11], brings people with disabilities into design teams as design partners. Newell, Gregor, and Alm [12] have brought together not only older adults and designers, but have also fostered get-togethers of older adults where learning of new technologies happens on a peer-to-peer basis, and have reported the benefits of this approach in regards to older adults' engagement in the design activities.

There are different challenges related to participatory design [13] and different challenges related, in particular, to research and design with and for older adults [14]. Our previous work has listed an array of difficulties that 6 researchers (R1-R6) experienced when setting up and conducting usability tests with older adults [5]. These at times support, and at other times add points to existing literature on the creation and upkeep of an older adult user group. The examples outlined above seem to suggest that retention of older adults in a group is an activity that is built not only outside design/research activities, but indeed within the activities themselves. One such example is the theatre promoted by Newell [15].

\section{Creating and Maintaining a User Network}

The existing literature on creating and maintaining groups of older adult users usually reports efforts for a single design or research project. We will go over existing recommendations and add our own experiences from the field.

\subsection{Recruiting Older Adults}

The challenge begins with finding a large enough number of older adults to take part in the activities. Some authors suggest resorting to nursing homes, day-care centres, and clubs, amongst others. We have found that these are all viable options, although, as Mody and co-workers [6] point out, reaching out to older adults in nursing homes may pose severe challenges. To build a user network encompassing diversity, we should target as many different institutions as we can. It often happens that if we remain with a single type of institution, we will have a narrow age range. 
Furthermore, when we study older adults, it is often the case that we are looking for specific chronic diseases or impairments. Our previous work has suggested that this is an important aspect for researchers [5]. The user network should be wide and diverse enough to secure participants with these specific characteristics.

In addition, researchers mentioned that in cases when they rely on information from staff at elder institutions where they go to conduct tests, or on the best of their own judgment, they might not get an adequate assessment of participants' cognitive abilities. Four participants [5] shared stories in which they realized that users were not able to conduct the tests already while the test was underway and at a time when there was no chance for them to turn back. In this context, reliable information regarding participants' particular abilities for the project at hand seems to be of paramount importance to researchers, as it helps avoiding stressful situations for both the practitioner and the older adult participant.

In order to set the terrain for future work, a previous screening should be made. This can be done by talking to the staff in the institutions and getting an idea of the type of group, and through a more formal screening using questionnaires for older adults to fill in with socio-demographic data, general health information or others that cover the specificities required for the tests or activities themselves. From our experience, it is also useful to take time to talk to each potential participant individually prior to conducting any screening, or even planning any activity. This helps us to understand the users, helps to create a relationship of trust and serves as an opportunity to explain to each potential participant what the user network is about.

During the initial contact with the institution it usually helps to mention other institutions in the area that are already part of the network, as it often happens that institutions know one another. In accordance with Eisma and co-workers' experience [10], we have also found that after the initial contact, and after formalizing the collaboration between the team and the end-user organization (i.e. a signed protocol), the first activity should take place within a short timeframe. Organizations of older adults are very much sought after. Therefore, it is advisable to maintain the contact, so that people do not suspect of researchers' intentions, nor forget about them. These activities may be design or research activities, but may very well be just a leisure activity with older adults.

\subsection{Maintaining Relationships with the Group}

It must be noted that, for the purpose of a user network that serves many different projects, a large number of older adults is required not only because of the sheer amount of design/research activities of each project, but also because practitioners should be careful not to convert them into a burden for the users in the group. Nevertheless, as going to meet the users is a recurrent activity in HCD, the designers/researchers come to learn through their experience about the groups, their idiosyncrasies, and routines. In day-care centres with which we work, older adults tend to strictly follow their routines and timetables, in particular regarding eating hours, as noted by one of our researchers. Learning about these may be useful for the design and research work [5], e.g.: 
If you try to apply the questionnaires closer to tea time they talk much less, because they know it is tea time and must get on with it. (R2)

Rubin and Chisnell [7] alert to the fact that, when welcoming older adults to one's facilities, arrangements should be made for a second person accompanying the first. Our experience confirms this need. As visiting the research centre facilities is a new experience that many users in the network look forward to, we should try to give all an opportunity to come over for research purposes. If this is not possible, we can invite older adults over just to get to know the facilities and the team.

Following the same line of thought, the person in charge of the user network should make sure to keep a record of activities being carried out and the users involved, so as to spread the activities between the available older adults as much as possible. The person should manage the amount and type of activities each user takes part in and make sure that participating in the activities is not a burden for the participants. Users in our network often take notice and complain that they have been less called upon for activities than others in the same group.

The people in charge of managing the user network should also make sure to share the outcomes of the design and research with the users. This helps people understand their contribution and helps to maintain the relationship.

Throughout time we gather much information in video or photographs. These materials are useful to publicize the network and recruit new users. However, it is crucial that we talk individually to each person who can be identified in these materials, so as to gather their authorization to make these materials public in any way. This authorization is signed apart from the particular informed consent used by the research project.

As a result of keeping a strong relationship with older adults and staff at the institutions, introducing the test sessions or other kinds of design/research activities becomes easier to practitioners.

\subsection{Training Researchers}

However carefully the relationships with the institutions and the users in the network might be managed, two fundamental points are i) to support, prepare and train researchers to address older adult users in the network and ii) to periodically gather their insights about their contacts with older adults [5]. The excerpts illustrating some of the points that we will be making in the following two sections were gathered during qualitative research with researchers, reported elsewhere [5].

\section{Support, Preparation and Training}

Contrary to what one might think, the age gap may lead to difficulties in communication between two generations. Our young researchers have reported that, on their first contacts with older adults in their research, not only did they have to pay special attention to language they used so that complex concepts could be communicated in laymen's terms, but they also actually reported being a bit fearful, on the first encounters, of talking to older adults they did not know because they were not used to talking 
to any older adults beyond their grandparents [5]. This is in line with the "cultural and experimental gap between researchers and older people" mentioned by Eisma and coworkers [10].

If for nothing else, working with and for older adults is a difficult line of work because of the emotional impact it can have on researchers. If contacts are frequent, researchers and users develop a relationship and older adults' personal problems, illnesses or death are likely to affect researchers. New team members need to be alerted and informed about this possibility and prepared to deal with these situations.

The case we are sharing in this paper is of a user network that needs to support multiple research projects. This means that, rather than dealing with the same group of researchers all the time, older adults in the network come to deal with a variety of researchers and a variety of research projects. In order to, on the one hand, support researchers in meeting the users for the first time and, on the other hand, to put users at ease, one person - the one in charge of managing the network, doing the recruitment, and so forth - will accompany researchers most of the times and introduce the activities. This person gives a face to the research centre and always bridges researchers and users. This person is also responsible for helping researchers plan ahead the time and resources they will need to conduct the various activities within their projects. Beyond that, this person is in charge of planning leisure activities (e.g. Christmas parties) and answering requests from the users or institutions in the network (e.g. demonstration of a particular project for an event). Other activities supporting the network are a website of its own, periodical newsletters or periodical dissemination of the network in specific fairs and events.

\section{Researchers' Insights}

Some of the users' reactions during user research or usability testing are completely unexpected to someone new to the field, but are part of everyday life for those working with the specific user group for a longer time. We have come to observe in time that there are some behaviour patterns within the network.

The experience (and tips) from more experienced researchers is useful to new researchers not only because it helps them plan ahead for some situations, but also deal in the moment with others. This, in turn will help make the best out of the research.

Researchers mentioned several examples of older adults' behaviour during the tests in regard to their own performance, their beliefs about themselves and their capabilities. Researchers commented that older adults in the network often felt they should try to help researchers out and even try to please or try not to look bad in front of researchers-a phenomenon which is documented in the literature concerning not only older adults, but participants in research as a whole [16].

Researchers furthermore comment that older adults they worked with tended to focus on the results of their performance, wanted to do well, and even sometimes regarded usability testing as a competition amongst test participants. In the following excerpt about the process for diary studies regarding games with older adults, the researcher illustrates this aspect of competition as well as the behaviour of older adults when trying to please the researchers: 
I went to the same [day-care] centre twice a week for a long time. (...) so I handed it [diary] over on a Tuesday, and when I got there on Thursday they would look at me, take out the little books and start filling them in, like "I didn't forget it, it's here, I'm doing it". (...) Sometimes they'd ask me if I could help them here and there (...) (R3)

In the same testimony, the researcher continues with an illustration of a behaviour associated with older adults' performance, which another researcher also noticed to be common - that older adults in the network often asked for approval or for help during the tests:

But that was the other thing, they always assumed that I would be evaluating their results: if they'd done well, if they'd done poorly, and it's hard for one to explain that there's no good or bad, and that we just wanted to know which things they liked best. And they insist a lot on that "But did I do well? But did I do badly? How did I do? But is that right, but is that wrong?" (R3)

Nevertheless, there might often be unexpected behaviours, such as the one described by researcher R3 during a diary study:

Eventually I stopped asking [for the diaries] because they said they had forgotten, didn't know where the books were anymore. One lady gave it to her grandson to do because she thought it was more fun for him. (R3)

In order to face these challenges, all interviewed researchers referred to the importance of having a user network at their service and, more specifically, a person who knows the people in the network and who helps them manage all that is related to the involvement of older adults in HCD.

\section{Discussion and Conclusions}

The experiences from the field reported in this paper refer to a particular set of over 350 users within a particular socio-cultural setting and might not be applicable to other settings. Some of the lessons learned are, however, aligned with existing reports in the literature.

The paper provides a brief overview of literature reports on the use of HCD with older adults and on the issue of creating and maintaining a user group. It complements existing knowledge by adding the authors' experience in the field and researchers' accounts of their experience with conducting design and research activities with older adults. The contributions of the paper are particularly novel in that they share lessons learned, methods and strategies to recruit and maintain an older adult user network to serve a wide array of projects. In our case the user network is treated as a project in itself, with its own management. One main conclusion is that the project should have, at least, a dedicated person to handle the network and preferably, as is our case, it helps that user network is a project in itself with its own human resources, tasks and budget. This has proved to be helpful for the researchers. 
Acknowledgments. The authors would like to express their gratitude to all the institutions, staff and users in the network (www.colaborar.fraunhofer.pt).

\section{References}

1. Directorate-General for Economic and Financial Affairs of the European Commission: The 2012 Ageing Report - Economic and Budgetary Projections for the 27 EU Member States (2010-2060). European Commission (2012)

2. Mykityshyn, A.L., Fisk, A.D., Rogers, W.A.: Learning to Use a Home Medical Device: Me-diating Age-Related Differences with Training. Human Factors 44(3), 354-364 (2002)

3. Rogers, W.A., Fisk, A.F., Mead, S.E., Walker, N., Cabrera, E.F.: Training Older Adults to Use Automatic Teller Machines. Human Factors 38, 425-433 (1996)

4. Nicolle, C.: USERfit - Design for All Methods and Tools. In: COST 219bis Seminar 'Human Aspects of Telecommunications for Disabled and Older People', Donostia-San Sebastián, Spain, June 11-12 (1999)

5. Correia de Barros, A., Leitão, R.: Young practitioners' challenges, experience and strategies in usability testing with older adults. In: Assistive Technology: From Research to Practice, AAATE 2013, pp. 787-792. IOS Press, Amsterdam (2013)

6. Mody, L., Miller, D.K., McGloin, J.M., Freeman, M., Marcantonio, E.R., Magaziner, J., Studenski, S.: Recruitment and Retention of Older Adults in Aging Research. Journal of the American Geriatrics Society 56(12), 2340-2348 (2009)

7. Rubin, J., Chisnell, A.L.: Handbook of Usability Testing: How to Plan, Design and Conduct Effective Tests. Wiley Publishing, Inc., Indianapolis (2008)

8. Lindsay, S., Jackson, D., Schofield, G., Olivier, P.: Engaging Older People Using Participatory Design. In: SIGCHI Conference on Human Factors in Computing Systems (CHI 2012), Austin, Texas, USA (2012)

9. Gregor, P., Newell, A.F.: Designing for Dynamic Diversity - Interfaces for Older People. In: The Fifth International ACM Conference on Assistive Technologies (ASSETS 2002), Edinburgh (2002)

10. Eisma, R., Dickinson, A., Goodman, J., Syme, A., Tiwari, L., Newell, A.F.: Early User Involvement in the Development of Information Technology-Related Products for Older People. Journal of Universal Access in the Information Society 3(2), 131-140 (2004)

11. Cassim, J.: Designing Effective User Interactions - Examples from the Challenge Workshops. In: 3rd Conference of the International Association for Universal Design IAUD, Hamamatsu, Japan (2010)

12. Newell, A.F., Gregor, P., Alm, N.: HCI for Older and Disabled People in the Queen Mother Research Centre at Dundee University, Scotland. In: CHI 2006 Extended Abstracts on Human Factors in Computing Systems (CHI EA 2006), Montréal, Québec, Canada (2006)

13. Vines, J., Clarke, R., Wright, P., McCarthy, J., Olivier, P.: Configuring Participation: On How We Involve People in Design. In: CHI 2013, Paris, France (2013)

14. Vines, J., Blythe, M., Lindsay, S., Dunphy, P., Monk, A., Olivier, P.: Questionable Concepts: Critique as a Resource for Designing with Eighty Somethings. In: CHI 2012, Austin, Texas, USA (2012)

15. Newell, A.F.: Design and the Digital Divide: Insights from 40 Years in Computer Support for Older and Disabled People. Morgan \& Claypool (2011)

16. Bertrand, M., Mullainathan, S.: Do People Mean What They Say? Implications for Subjective Survey Data. The American Economic Review 91(2), 67-72 (2001) 